\title{
The effect of single doses of pramlintide on gastric emptying of two meals in men with IDDM
}

\author{
M.-F. Kong ${ }^{1}$, T. A.Stubbs ${ }^{2}$, P. King ${ }^{1}$, I. A. Macdonald ${ }^{2}$, J. E. Lambourne ${ }^{2}$, P. E. Blackshaw ${ }^{3}$, A. C. Perkins ${ }^{3}$, \\ R.B. Tattersall ${ }^{1}$ \\ ${ }^{1}$ Department of Diabetes, University Hospital, Queen's Medical Centre, Nottingham, UK \\ ${ }^{2}$ School of Biomedical Sciences, University of Nottingham Medical School, Nottingham, UK \\ ${ }^{3}$ Department of Medical Physics, University Hospital Nottingham and University of Nottingham Medical School, Nottingham, \\ UK
}

\begin{abstract}
Summary In a previous study we have shown that an intravenous infusion of pramlintide (an analogue of human amylin) delayed gastric emptying, but the dose of pramlintide was supraphysiological in relation to the amylin response to food in non-diabetic subjects. The purpose of this study was to examine the dose response relationship of subcutaneous injections of pramlintide on gastric emptying and to determine whether administration of the drug before one meal has an impact on the subsequent meal. Eleven men with insulin-dependent diabetes mellitus were studied in a double-blind, randomised, four-way crossover design. None had autonomic neuropathy. Euglycaemia was maintained overnight before the study day. At -30 min the patients self-injected their usual morning insulin and at -15 min they injected the study drug (either placebo or 30,60 or $90 \mu \mathrm{g}$ pramlintide) subcutaneously. At 0 min they ate a standard meal consisting of a pancake, labelled with
\end{abstract}

${ }^{99 \mathrm{~m}} \mathrm{Tc}$, and a milkshake containing 3-ortho-methylglucose (3-OMG). Gastric emptying images were obtained for the next $8 \mathrm{~h}$. At $240 \mathrm{~min}$ the subjects ate a similar meal, but on this occasion the pancake was labelled with ${ }^{111} \mathrm{In}$. All three doses of pramlintide delayed emptying of the solid component of the first meal $(p<0.004)$ with no significant difference between the drug doses. There were no differences between placebo and pramlintide after the second meal. All three doses of pramlintide resulted in a prolongation in the time to peak plasma 3-OMG level $(p<0.0001)$ after the first meal but there was no difference after the second meal. [Diabetologia (1998) 41: 577-583]

Keywords Insulin-dependent diabetes mellitus, gastric emptying, postprandial hyperglycaemia, amylin, pramlintide.
Gastric emptying is a significant determinant of the blood glucose response after an oral carbohydrate load [1] due to the key role this process plays in regulating the rate of nutrient delivery to the small intestine. Gastric emptying may therefore be a previously under-recognized contributor to variations in glycae-

Received: 22 September 1997 and in revised form: 14 January 1998

Corresponding author: Professor I. A. Macdonald, School of Biomedical Sciences, University of Nottingham Medical School, Nottingham NG7 2UH, UK

Abbreviations: IDDM, Insulin-dependent diabetes mellitus; 3OMG, 3-ortho-methylglucose; AUC, area under the curve; ROIs, regions of interest; $\mathrm{CV}$, coefficient of variation. mic control in diabetes mellitus. Faster rates of gastric emptying have been reported not only in rat models of insulin-dependent diabetes mellitus (IDDM) $[2,3]$ but also in patients with IDDM $[4,5]$ and recent studies suggest that modulation of gastric emptying could be used to improve glycaemic control in patients with diabetes [6].

Amylin is a 37 amino acid polypeptide co-secreted with insulin by pancreatic beta cells, in response to nutrient stimuli. It circulates at concentrations of 5-30 pmol/1 in normal subjects. IDDM patients are not only insulin deficient but also amylin deficient [7, 8]. Amylin concentrations in IDDM patients range from the lower end of the normal range to undetectable and do not increase in response to a glucose load. The peptide pramlintide is a stable trisub- 
stituted non-aggregating analogue of amylin [9] which in animal studies has biological activities similar to endogenous amylin.

In a previous study we have shown that an intravenous infusion of pramlintide delayed gastric emptying in men with IDDM but the dose of pramlintide was supraphysiological in relation to the amylin response to food in non-diabetic subjects [10]. The purpose of this study was to examine the dose response effect of pramlintide on gastric emptying and to determine the duration of any effect by assessing whether administration of the drug before one meal has an impact on the subsequent meal.

\section{Subjects and methods}

Subjects. Eleven healthy non-obese men (BMI $23.2 \pm 0.8 \mathrm{~kg} /$ $\mathrm{m}^{2}$, mean \pm SEM, range 19-26.6) with uncomplicated IDDM, aged $28 \pm 2.1$ years (mean \pm SEM, range 20.6-42.1) were recruited. Mean duration of diabetes was $12.3 \pm 2.3$ years (mean \pm SEM, range 0.8-27.5) and $\mathrm{HbA}_{1 \mathrm{c}}$ was $9.5 \pm 0.7 \%$ (mean \pm SEM, range 6.1-14.6, normal up to $6.1 \%$ for the assay, SciCor Laboratories, Geneva, Switzerland). All had a basal Cpeptide level less than $1.0 \mathrm{ng} / \mathrm{ml}$ (analysed at Laboratoire Riotton, Geneva, Switzerland), and were on no medication apart from insulin. None had autonomic neuropathy, as assessed clinically and by tests of cardiovascular reflexes, including the heart rate response to the valsalva manoeuvre, during deep breathing and on standing (30:15 ratio). Informed consent was obtained from all subjects. The study was approved by the British Department of Health (Administration of Radioactive Substances Advisory Committee) and the Research Ethics Committee of the University Hospital, Queen's Medical Centre, Nottingham.

Protocol. Each subject had four gastric emptying studies in a randomized, double-blind, placebo-controlled four-way crossover design. Subjects were admitted on the evening before the study day and had euglycaemia (blood glucose 5-8 mmol/ 1) maintained overnight by intravenous infusion of insulin and/or glucose. A cannula was inserted into an antecubital vein for hourly blood glucose sampling and subsequently used for infusion of glucose, as required. The next morning another cannula was inserted retrogradely, under local anaesthetic, into a vein on the dorsum of the dominant hand; it was kept patent with a slow infusion of $0.9 \% \mathrm{NaCl}$ and the hand rested in a heated box $\left(55-60^{\circ} \mathrm{C}\right)$ to obtain "arterialized" venous blood samples.

Low-activity radioactive anatomical markers $\left({ }^{99 \mathrm{~m}} \mathrm{Tc}\right)$ were attached to the surface of the subject's skin, anteriorly and posteriorly. Thirty minutes before they were due to eat, the patients injected themselves with their usual morning insulin and $15 \mathrm{~min}$ later they injected the study drug (either placebo or 30,60 or $90 \mu \mathrm{g}$ pramlintide) subcutaneously. Arterialized blood samples were taken for estimation of blood glucose, plasma 3-ortho-methylglucose (3-OMG), and insulin at -40 , -30 and immediately prior to consumption of the standard breakfast meal. At $0 \mathrm{~min}$, within $10 \mathrm{~min}$, they ate a standard meal consisting of a pancake, labelled with $3 \mathrm{MBq}$ non-absorbable Tc-99m-ion exchange resin, and a low fat milkshake containing 3-OMG so that its appearance in the peripheral circulation could be used as an index of glucose absorption. The meal consisted of $50 \%$ carbohydrate, $35 \%$ fat, $15 \%$ pro- tein, providing a total of $500 \mathrm{kcal}$. Gastric emptying images were obtained for the next $8 \mathrm{~h}$. At 240 min the subjects ate a similar meal, but on this occasion the pancake was labelled with ${ }^{111} \mathrm{In}$.

Gastric emptying data were acquired with $30 \mathrm{~s}$ anterior and posterior images of the stomach [11] every 20 min using an IGE maxi-camera II gamma camera (IGE Medical Systems, Slough, UK) fitted with a medium-energy general purpose collimator. The gamma camera was linked to a dedicated nuclear diagnostics nuclear medicine computer system. Regions of interest (ROIs) were created around the computer generated image of the stomach for both anterior and posterior images, and counts were recorded. The geometric mean of the anterior and posterior measurements was calculated and counts were corrected for background radiation, isotope decay and cross talk between the energy windows. For each of the three ROIs (proximal, distal, and total stomach), activity time curves, expressed as a percentage of total meal against time, were derived. Various emptying parameters were calculated from these curves. The coefficient of variation $(\mathrm{CV})$ for solid $t_{50}$ in normal subjects was $13 \%$.

Arterialised blood samples, for measurement of 3-OMG and free insulin were taken at regular intervals. Blood glucose was measured every $10 \mathrm{~min}$ after the meal using a Yellow Springs Analyser (Yellow Springs, Ohio, USA); CV for the assay was $3 \%$. Plasma was stored in fluoride oxalate for subsequent determination of 3-OMG by gas-liquid chromatography $[12,13]$ (intra-assay CV 1.8-5.7\%). Serum insulin concentrations were analysed at SciCor, Inc., Indianapolis, Ind., USA (intra-assay CV 2.7-4.6\%, inter-assay CV 6.3-9.7\%). Arterialised blood samples were taken at regular intervals for pramlintide measurements which were assayed using a validated immunoradiometric assay (IRMA) method at Amylin Pharmaceuticals Inc., San Diego, Calif., USA (intra-assay CV $3.4-5.5 \%$, inter-assay CV 5.2-5.5\%).

Glucose was infused, as required, if a subject's blood glucose fell below $5 \mathrm{mmol} / \mathrm{l}$ at any time during the study, following the meal.

Patients returned to the clinic after 7-14 days for the next randomised treatment.

Statistical analysis. Conventional methods were used to calculate means, medians, SEM and SD. The null hypothesis tested for all of the efficacy analyses was that there was no difference among the study drug regimens. The alternative hypothesis is that a difference exists. Since this was a four-period crossover trial, tests were also performed to check for period, carryover, and sequence effects. Four-period crossover analysis of variance methods were used to test for study drug effects, period effects, carryover effects, and sequence effects [14]. If the appropriate ANOVA assumptions were not met, a Wilcoxon test, based on ranks, for crossover analyses was used. The Hochberg adjustment for multiple comparisons [15] was used to test for treatment differences from placebo. Blood glucose at the different time points and the AUC from time 0-240 $\mathrm{min}$ and 240-480 min were also analysed using 2-tailed $t$-test. A $p$ value less than 0.05 was considered significant in all analyses.

The lag time was defined as the delay between the ingestion of food and definite start of emptying (this is taken as the time taken for at least $10 \%$ of isotope to empty) and $t_{50}$ was defined as the time at which $50 \%$ of the isotope had left the stomach.

The area under the curve (AUC) was calculated using the trapezoidal rule. Zero-hour AUC (the area under the serum or blood level-time curve above the zero-hour value) was calculated from 3-OMG and blood glucose concentrations adjusted for baseline concentration. 


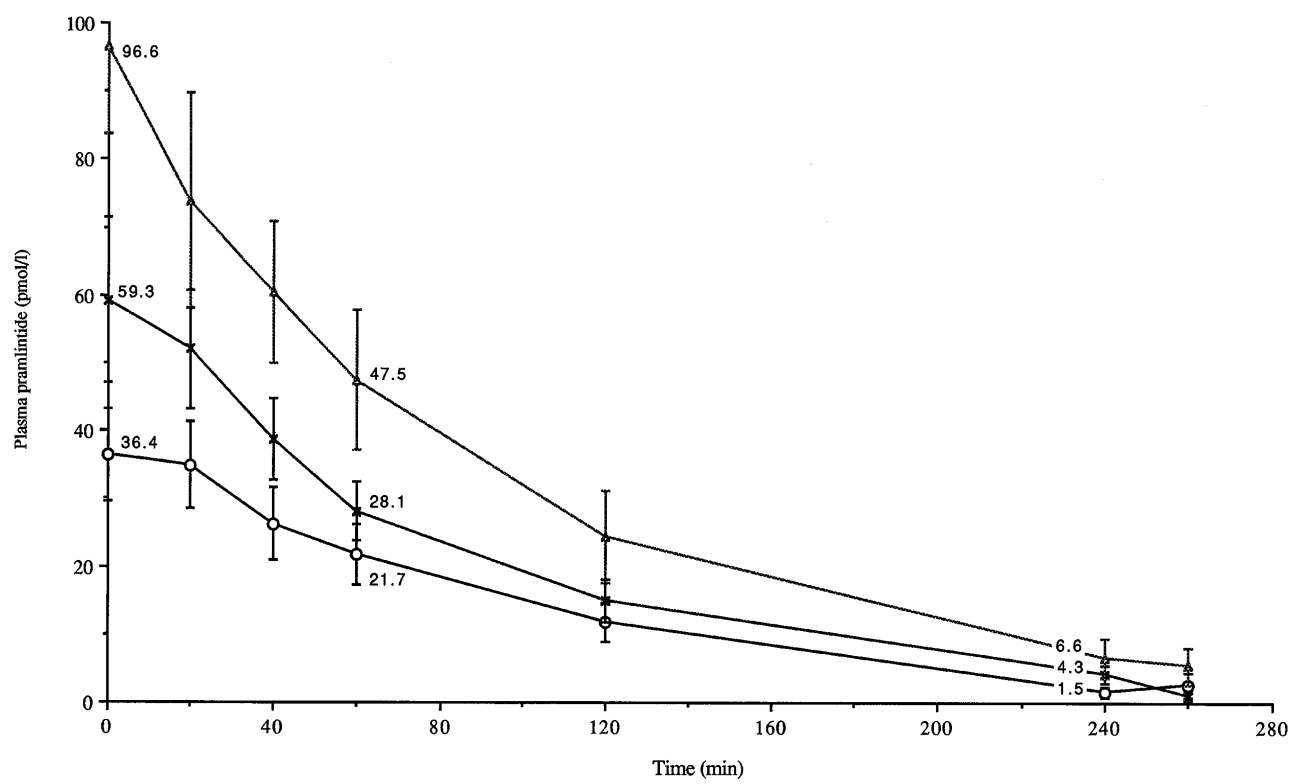

Fig. 1. Pramlintide concentrations after $30 \mu \mathrm{g}(-\mathrm{o}-), 60 \mu \mathrm{g}(-\mathrm{x}-)$ and $90 \mu \mathrm{g}(-\Delta-)$ injections

\section{Results}

Patients self-injected their usual morning insulin at -30 min and at -15 min they injected the study drug (either placebo or 30,60 or $90 \mu \mathrm{g}$ pramlintide) subcutaneously. At 0 min they ate a standard meal and at 240 min they ate a similar meal. Five subjects had insulin injections at $210 \mathrm{~min}$. Gastric emptying images were taken at $20 \mathrm{~min}$ intervals from time 0 to $480 \mathrm{~min}$.

Plasma pramlintide (Fig. 1). The mean plasma pramlintide concentrations at time 0, 60, $240 \mathrm{~min}$ were $36.4 \pm 6.8 \mathrm{pmol} / \mathrm{l}, \quad 21.7 \pm 4.4 \mathrm{pmol} / \mathrm{l}$ and $1.5 \pm$ $0.8 \mathrm{pmol} / \mathrm{l}$, respectively when $30 \mu \mathrm{g}$ pramlintide was injected, $59.3 \pm 12.1 \mathrm{pmol} / \mathrm{l}, \quad 28.1 \pm 4.4 \mathrm{pmol} / \mathrm{l}$ and $4.3 \pm 1.4 \mathrm{pmol} / \mathrm{l}$, respectively when $60 \mu \mathrm{g}$ pramlintide was injected and $96.6 \pm 12.8 \mathrm{pmol} / 1,47.5 \pm 10.5 \mathrm{pmol} /$ 1 and $6.6 \pm 2.9 \mathrm{pmol} / \mathrm{l}$, respectively when $90 \mu \mathrm{g}$ pramlintide was injected.

Blood glucose (Fig. 2). There were no differences between the three doses of pramlintide and placebo in the overall patterns of blood glucose response after either meal (no significant difference in AUC from time 0-240 and 240-480 min). However, the AUC from time 0-120 min was significantly lower when $60 \mu \mathrm{g}$ and $90 \mu \mathrm{g}$ pramlintide were injected ( $p=0.0101$ and $p=0.0215$, respectively) but there was no significant difference from placebo in the AUC over the same time interval when the $30 \mu \mathrm{g}$ dose was injected $(p=0.1815)$. It took longer to reach peak blood glucose when 60 and $90 \mu \mathrm{g}$ pramlintide were injected but not when $30 \mu \mathrm{g}$ pramlintide was injected $(91.8 \pm 17.6,111.8 \pm 26.2,165.1 \pm 20.9,161.8 \pm$ 26.7 min after placebo, 30, 60 and $90 \mu \mathrm{g}$ pramlintide injections, respectively). The peak glucose values after breakfast were $11.4 \pm 1.1 \mathrm{mmol} / \mathrm{l}$ at $80 \mathrm{~min}$, $10.4 \pm 1.2 \mathrm{mmol} / 1$ at $200 \mathrm{~min}, 10.2 \pm 1.6 \mathrm{mmol} / 1$ at $210 \mathrm{~min}, 11.1 \pm 1.4 \mathrm{mmol} / \mathrm{l}$ at $210 \mathrm{~min}$ after placebo, 30, 60 and $90 \mu \mathrm{g}$ pramlintide injections, respectively. The corresponding values after lunch were $14.4 \pm 2.1 \mathrm{mmol} / \mathrm{l}$ at $370 \mathrm{~min}, 11.7 \pm 1.9 \mathrm{mmol} / 1$ at $300 \mathrm{~min}, 12.5 \pm 1.6$ at $310 \mathrm{~min}$ and $12.4 \pm 1.5 \mathrm{mmol} / \mathrm{l}$ at $310 \mathrm{~min}$, respectively.

Serum insulin. There were no differences between the three doses of pramlintide and placebo in the insulin profile after either meal (no significant difference in AUC).

3-OMG (Fig. 3). When compared to placebo, plasma 3-OMG AUC corrected for the zero-hour value was significantly lower after the first meal after all three doses of pramlintide $(40.5 \pm 3.1$ vs $29.5 \pm 3.8$, $27.7 \pm 4.3, \quad 25.6 \pm 2.5 \mathrm{mmol} \cdot \mathrm{min}^{-1}, \quad$ respectively, $p<0.02$ ) but there was no difference after the second meal. All three doses of pramlintide resulted in a prolongation in the time to peak plasma $3-\mathrm{OMG}$ level after the first meal $\left(\mathrm{T}_{\max } 65.0 \pm 3.3,175.5 \pm 16.9\right.$, $192.5 \pm 19.2,213.3 \pm 19.0 \mathrm{~min}$ after placebo, 30, 60 and $90 \mu \mathrm{g}$ pramlintide injections, respectively; $p<0.0001$ ) but there was no difference after the second meal $\left(\mathrm{T}_{\max } 312.5 \pm 9.2,318.0 \pm 10.9,330.0 \pm 23.6\right.$, $310.0 \pm 6.5 \mathrm{~min}$, respectively).

Effect on solid gastric emptying (Fig. 4 and Fig.5). The figures for the proximal and distal distribution of the meal are shown for illustrative purposes. Statistical analysis was only performed on the "total stomach" emptying data; the results for the proximal 


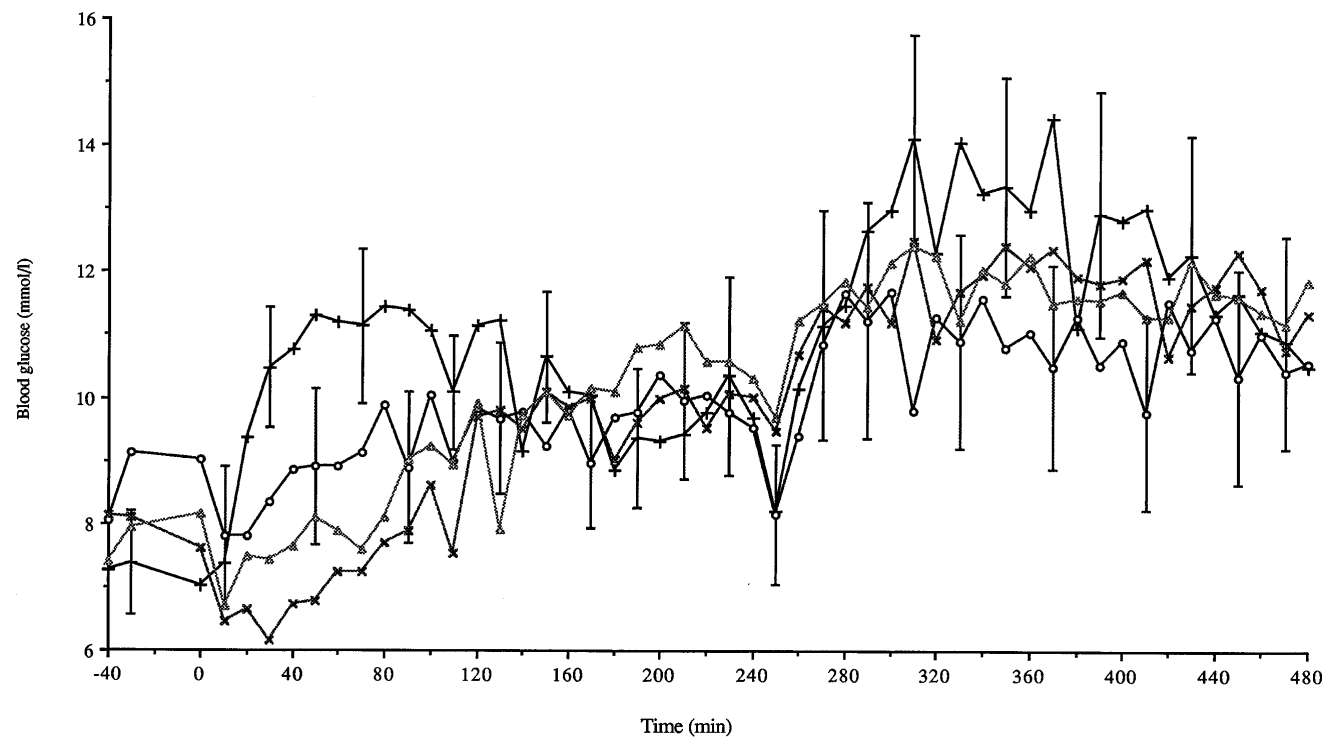

Fig. 2. Blood glucose after placebo (-+-), $30 \mu \mathrm{g}(-\mathrm{o}-), 60 \mu \mathrm{g}$ $\left(-\mathrm{x}^{-}\right)$and $90 \mu \mathrm{g}\left(-\Delta^{-}\right)$injections. There were no differences between the three doses of pramlintide and placebo in the overall patterns of blood glucose response after either meal (no significant difference in AUC from time 0-240 and 240-480 min). However, the AUC from time 0-120 min was significantly lower when 60 and $90 \mu \mathrm{g}$ pramlintide were injected $(p=0.0101$ and $p=0.0215$, respectively) but there was no significant difference in the AUC over the same time interval when the $30 \mu \mathrm{g}$ dose was injected $(p=0.1815)$

Fig.3. Plasma 3-OMG after placebo (-+-), $30 \mu \mathrm{g}(-\mathrm{o}-), 60 \mu \mathrm{g}$ $\left(-\mathrm{X}^{-}\right)$and $90 \mu \mathrm{g}\left(-\Delta^{-}\right)$injections. When compared to placebo, plasma 3-OMG AUC corrected for the zero-hour value was significantly lower after the first meal after all three doses of pramlintide $\quad(40.5 \pm 3.1$ vs $29.5 \pm 3.8, \quad 27.7 \pm 4.3, \quad 25.6 \pm$ $2.5 \mathrm{mmol} \cdot \operatorname{min~} \mathrm{l}^{-1}$, respectively, $\left.p<0.02\right)$ but there was no difference after the second meal. All three doses of pramlintide resulted in a prolongation in the time to peak plasma $3-\mathrm{OMG}$ level after the first meal $(p<0.0001)$ and distal stomach are shown in the figures and described qualitatively.

All three doses of pramlintide delayed emptying of the solid component of the first meal $(p<0.02$ for the lag time and $p<0.004$ for $\mathrm{t}_{50}$ ) with no difference between the drug doses. The mean lag times were $32.5 \pm 7.2, \quad 54.4 \pm 6.8, \quad 56.4 \pm 8.0, \quad 70.3 \pm 14.6$ min and the mean $\mathrm{t}_{50}$ values were $128.6 \pm 20.4$, $187.2 \pm 14.0,200.1 \pm 17.0$ and $214.5 \pm 22.5 \mathrm{~min}$ for placebo, 30, 60 and $90 \mu \mathrm{g}$ pramlintide, respectively, (Fig. $4 \mathrm{a}$ and Fig. 5a). There were no differences between placebo and pramlintide after the second meal. The lag times were $34.2 \pm 7.3$, $46.5 \pm 8.6,40.0 \pm 6.5,48.2 \pm 8.9 \mathrm{~min}$ and the $\mathrm{t}_{50}$ values were $136.9 \pm 13.5,138.5 \pm 11.1,140.6 \pm 11.0$ and $145.4 \pm 13.6$, respectively (Fig. $4 \mathrm{~b}$ ). Thus, there was a delay of both the initial phase and the first $50 \%$ of gastric emptying of the first meal but there was no effect on the second meal. The slower emptying after pramlintide injection could largely be ex-

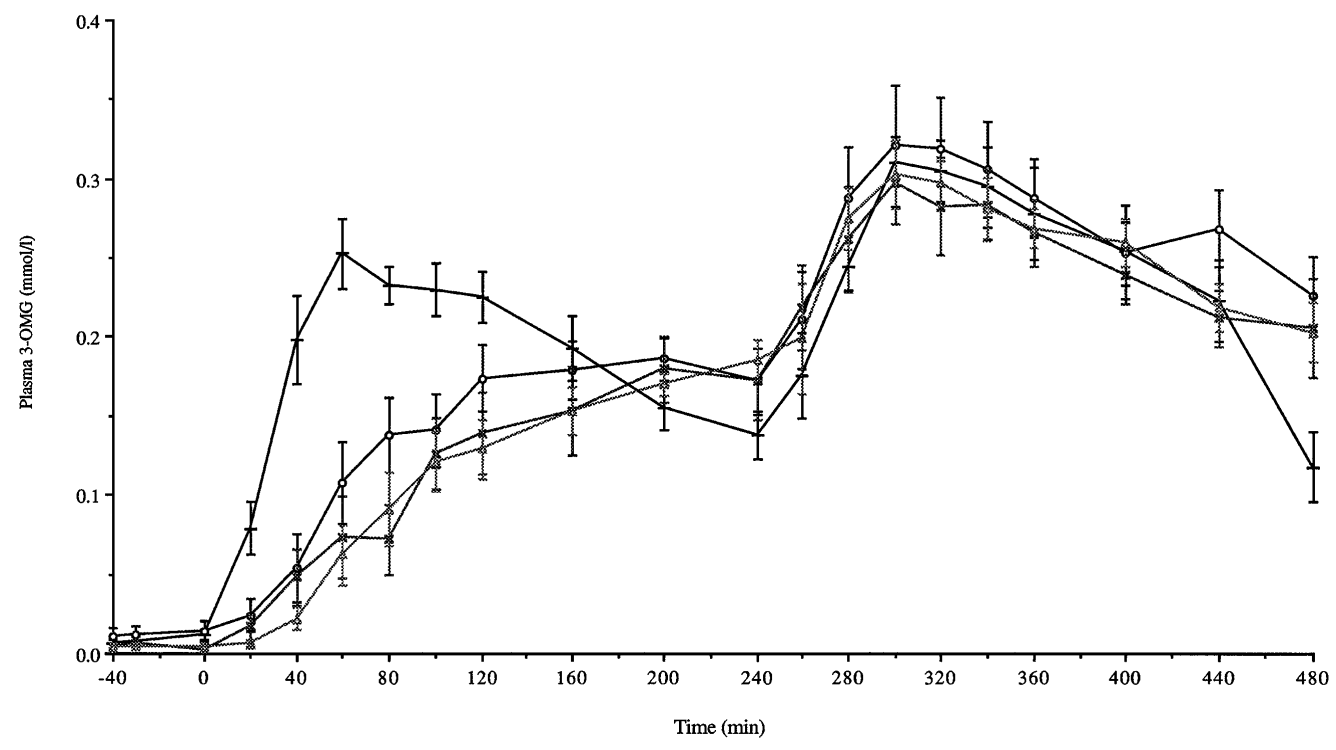




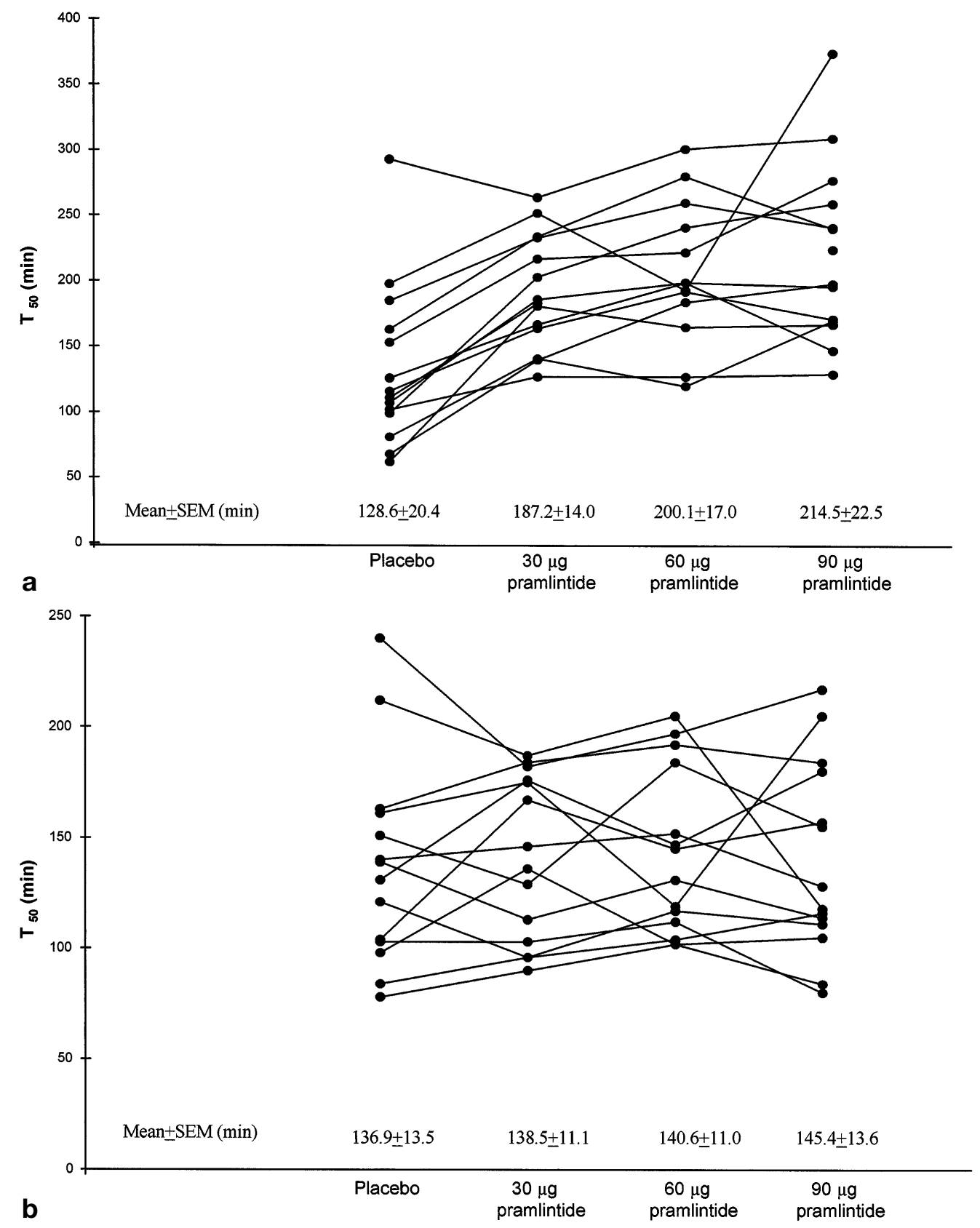

Fig. 4 (a). Half-emptying times $\left(t_{50}\right)$ of the solid component of the first meal after placebo, $30 \mu \mathrm{g}, 60 \mu \mathrm{g}$ and $90 \mu \mathrm{g}$ injections. All three doses of pramlintide delayed emptying of the solid component of the first meal $(p<0.004)$ with no difference between the drug doses. (b) Half-emptying times $\left(t_{50}\right)$ of the solid component of the second meal after placebo, $30 \mu \mathrm{g}, 60 \mu \mathrm{g}$ and $90 \mu \mathrm{g}$ injections. There were no differences between placebo and pramlintide after the second meal

plained by retention in the proximal stomach (Fig. 5 b).

The study protocol was well tolerated by all subjects but nausea and vomiting occurred in one patient when he had the $60 \mu \mathrm{g}$ injection. One patient reported nausea when he received placebo. Hypoglycaemia occurred in two patients when on placebo (blood glucose values of $3.8 \mathrm{mmol} / \mathrm{l} 50 \mathrm{~min}$ after the second meal and $3.3 \mathrm{mmol} / \mathrm{l} 4 \mathrm{~h}$ after the first meal) and in one patient in each of the three pramlintide groups (blood glucose values of $3.8 \mathrm{mmol} / \mathrm{l} 170 \mathrm{~min}$ after the second meal, $3.4 \mathrm{mmol} / 120 \mathrm{~min}$ after the first meal and $3.0 \mathrm{mmol} / 110 \mathrm{~min}$ after the first meal).

\section{Discussion}

The rate of gastric emptying can be affected by a large number of factors such as meal composition, blood glucose concentration and insulinaemia. To avoid potential influence of meal content, the study was designed as a crossover trial and a standardized 

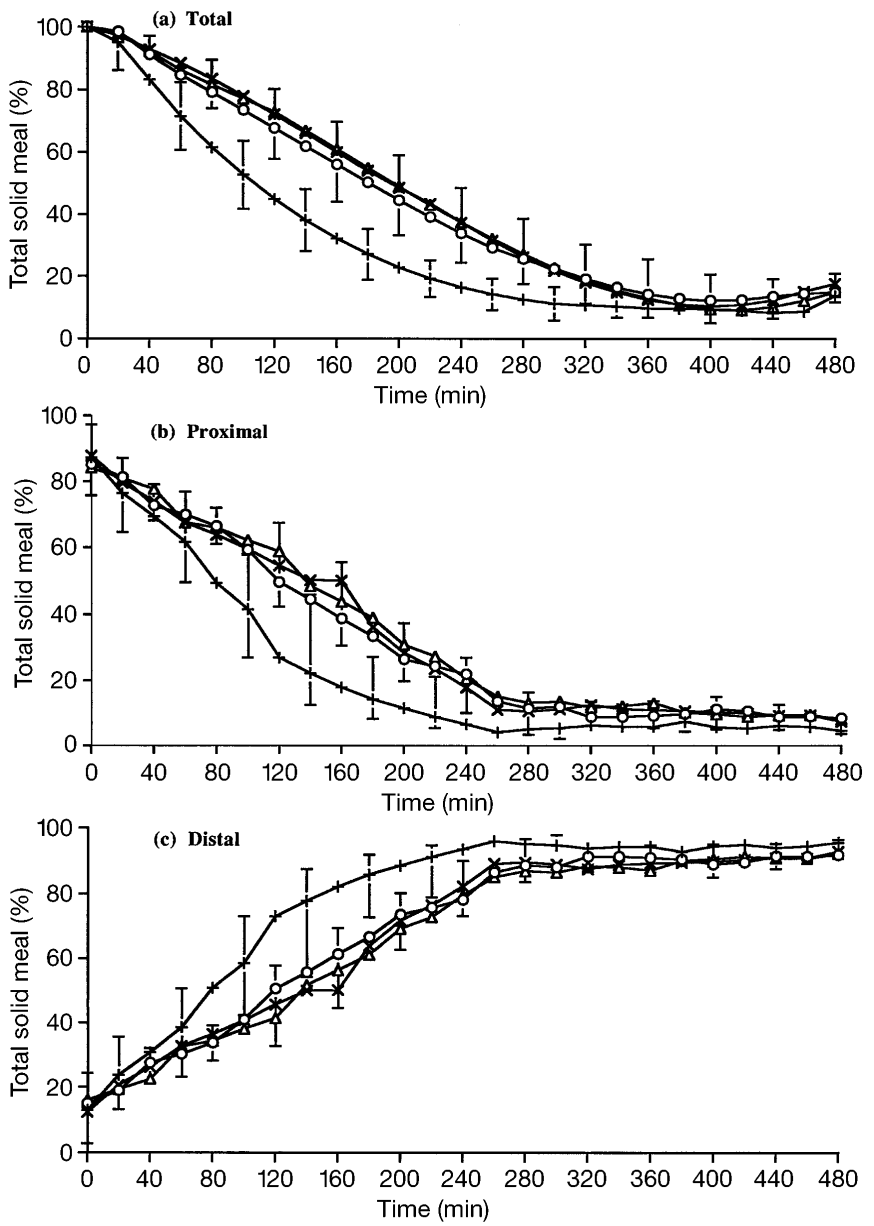

Fig.5a-c. Solid gastric emptying of the first meal after placebo (-+-), $30 \mu \mathrm{g}(-\mathrm{o}-), 60 \mu \mathrm{g}(-\mathrm{x}-)$ and $90 \mu \mathrm{g}(-\Delta-)$ injections. Data are median and interquartile ranges, a total; b proximal; c distal. There was a delay of both the initial phase and the first $50 \%$ emptying. The slower emptying after pramlintide injection could largely be explained by retention in the proximal stomach

test meal used. Hyperglycaemia is known to delay gastric emptying in both normal subjects and patients with diabetes [16-18]. The delayed gastric emptying after the first meal when pramlintide was injected was not related to postprandial hyperglycaemia; compared to placebo the AUC from time 0-120 min was significantly lower when 60 and $90 \mu \mathrm{g}$ pramlintide were injected but there was no significant difference in the AUC when the $30 \mu \mathrm{g}$ dose was injected. Thus, injections of 60 and $90 \mu \mathrm{g}$ pramlintide resulted in a delay of gastric emptying which was not due to a greater hyperglycaemic response than the placebo injection.

Hyperinsulinaemia (approximately $270 \mathrm{pmol} / \mathrm{l}$ ) has been reported to delay gastric emptying in normal subjects [19]. In the present study, there were no differences between the three doses of pramlintide and placebo in the insulin profile after either meal.
Therefore, the delay in gastric emptying after pramlintide injection was not an effect of insulin.

Following gastric emptying glucose is transported across the intestinal wall and enters the circulation. Its absorption rate can be estimated using double isotope labelling techniques. However, since 3-OMG is actively transported across the small intestine [20], but is not metabolized after absorption [21], this glucose analogue can serve as an indicator of active monosaccharide absorption. Delayed absorption of 3-OMG would be consistent with an effect secondary to delayed gastric emptying. In the present study, the absorption of 3-OMG was delayed after all three doses of pramlintide after the first meal which was probably secondary to the delay of gastric emptying. There was no difference after the second meal.

The delayed gastric emptying of the solid component of the meal by subcutaneous injections of pramlintide appears to be due to its retention in the proximal stomach region. Collins et al. [22] have reported that a dextrose drink delayed gastric emptying of a solid meal, compared with saline, by increasing the lag period and retention in the proximal stomach. This could possibly be due to a delay of emptying caused by endogenous amylin and/or insulin which will have been co-secreted in response to the glucose drink. Thus, subcutaneous injections of pramlintide cause retention of food in the proximal stomach, similar to an intravenous infusion of pramlintide [10]. This may be an extension of the effects of glucose described by Collins et al. [22].

In our previous study an intravenous infusion of pramlintide was used and the peak plasma concentration achieved was $130.3 \pm 18.9 \mathrm{pmol} / \mathrm{l}$. Fasting plasma amylin concentrations range between 4 and $11 \mathrm{pmol} / 1$ in normal subjects and increase $2-3$ fold following a mixed meal or during an oral glucose tolerance test $[23,24]$. The $30,60,90 \mu \mathrm{g}$ pramlintide injections achieved plasma concentrations of $21.7 \pm 4.4$, $28.1 \pm 4.4$ and $47.5 \pm 10.5 \mathrm{pmol} / 1$, respectively at time $60 \mathrm{~min}$. The lag time and the delay in $\mathrm{t}_{50}$ after the first meal when pramlintide was injected provide some indication of a necessary concentration of pramlintide for an effect on gastric emptying. The lack of effect after the second meal confirms that the plasma pramlintide concentration needs to be more than $10 \mathrm{pmol} / \mathrm{l}$ to have an effect on gastric emptying.

Acknowledgements. We wish to thank Dr. Simon Fleming (Department of Clinical Chemistry, Royal Cornwall Hospital, Truro, Cornwall, UK) for performing the plasma 3-OMG assays and Dr. M.Frier (Radiopharmacy Unit, University of Nottingham Medical School) for dispensing and drug accountability and Amylin Pharmaceuticals Inc. (San Diego, USA) and Amylin Europe Ltd (Oxford, UK) for financial support. 


\section{References}

1. Horowitz M, Edelbroek M, Wishart J, Straathof J (1993) Relationship between oral glucose tolerance and gastric emptying in normal healthy subjects. Diabetologia 36: 857-862

2. Young AA, Gedulin B, Vine W, Percy A, Rink TJ (1995) Gastric emptying is accelerated in diabetic $\mathrm{BB}$ rats and is slowed by subcutaneous injections of amylin. Diabetologia 38: 642-648

3. Nowak TV, Roza AM, Weisbruch JP, Brosnan MR (1994) Accelerated gastric emptying in diabetic rodents: effect of insulin treatment and pancreas transplantation. J Lab Clin Med 123: 110-116

4. Nowak TV, Johnson CP, Kalbfleisch JH et al. (1995) Highly variable gastric emptying in patients with insulin dependent diabetes mellitus. Gut 37: 23-29

5. Keshavarzian A, Iber FL, Vaeth J (1987) Gastric emptying in patients with insulin requiring diabetes mellitus. Am J Gastroenterol 82: 29-35

6. Kolterman OG, Gottlieb A, Moyses C, Colburn W (1995) Reduction of postprandial hyperglycaemia in subjects with IDDM by intravenous infusion of AC137, a human amylin analogue. Diabetes Care 18: 1179-1182

7. Bennet WM, Smith DM, Bloom SR (1994) Islet amyloid polypeptide: does it play a pathophysiological role in the development of diabetes? Diabet Med 11: 825-829

8. Koda JE, Fineman M, Rink TJ, Dailey GE, Muchmore DB, Linarelli LG (1992) Amylin concentrations and glucose control. Lancet 339: 1179-1180

9. Rink TJ, Beaumont K, Koda J, Young A (1993) Structure and biology of amylin. Trends Pharmacol Sci 14: 113-118

10. Kong M-F, King P, Macdonald IA et al. (1997) Infusion of pramlintide, a human amylin analogue, delays gastric emptying in men with IDDM. Diabetologia 40: 82-88

11. Hardy JG, Perkins AC (1985) Validity of the geometric mean correction in the quantification of whole bowel transit. Nucl Med Commun 6: 217-224
12. Laker MF, Mount JN (1980) Mannitol estimation in biological fluids by gas-liquid chromatography of trimethylsilyl derivatives. Clin Chem 26: 441-443

13. Laker MF (1979) Estimation of disaccharides in plasma and urine by gas-liquid chromatography. J Chromatogr 163: $9-18$

14. Fleiss JL (1986) The design and analysis of clinical experiments. John Wiley \& sons, New York, pp 263-290

15. Hochberg Y (1988) A sharper Bonferroni procedure for multiple tests of significance. Biometrika 75: 800-802

16. MacGregor I, Gueller R, Watts H, Meyer J (1976) The effects of acute hyperglycaemia on gastric emptying in man. Gastroenterology 70: 190-196

17. Fraser R, Horowitz M, Maddox A, Harding P, Chatterton B, Dent J (1990) Hyperglycaemia slows gastric emptying in type 1 (insulin-dependent) diabetes mellitus. Diabetologia 33: 675-680

18. Horowitz M, Harding P, Maddox AF et al. (1989) Gastric and oesophageal emptying in patients with type 2 (non-insulin-dependent) diabetes mellitus. Diabetologia 32: 151-159

19. Eliasson B, Björnsson E, Urbanavicius V et al. (1995) Hyperinsulinaemia impairs gastrointestinal motility and slows carbohydrate absorption. Diabetologia 38: 79-85

20. Laker MF, Bull HJ, Menzies IS (1982) Evaluation of mannitol for use as a probe marker of gastrointestinal permeability in man. Eur J Clin Invest 12: 485-491

21. Fordtran JS, Clodi PH, Soergel KH, Ingelfinger FJ (1962) Sugar absorption tests, with special reference to 3-O-methyl-D-glucose and D-xylose. Ann Intern Med 57: 883-891

22. Collins PJ, Houghton LA, Read NW et al. (1991) Role of the proximal and distal stomach in mixed solid and liquid meal emptying. Gut 32: 615-619

23. Hartter E, Svoboda T, Ludvik B et al. (1991) Basal and stimulated plasma levels of pancreatic amylin indicate its cosecretion with insulin in humans. Diabetologia 34: 52-54

24. Butler PC, Chou J, Carter B et al. (1990) Effects of meal ingestion on plasma amylin concentrations in NIDDM and non-diabetic humans. Diabetes 39: 752-756 